\title{
Calculating of stress intensity factors of soldered joints with multiple cracks
}

\author{
Al Emran Ismail, Kamarul Azhar Kamarudin, Mohd Khir Mohd Nor, Ahmad Mubarak Tajul Arifin, \\ Mohd Fahrul Hassan, Mohd Rasidi Ibrahim and Mohammad Zulafif Rahim \\ Faculty of Mechanical and Manufacturing Engineering, Universiti Tun Hussein Onn Malaysia, Malaysia
}

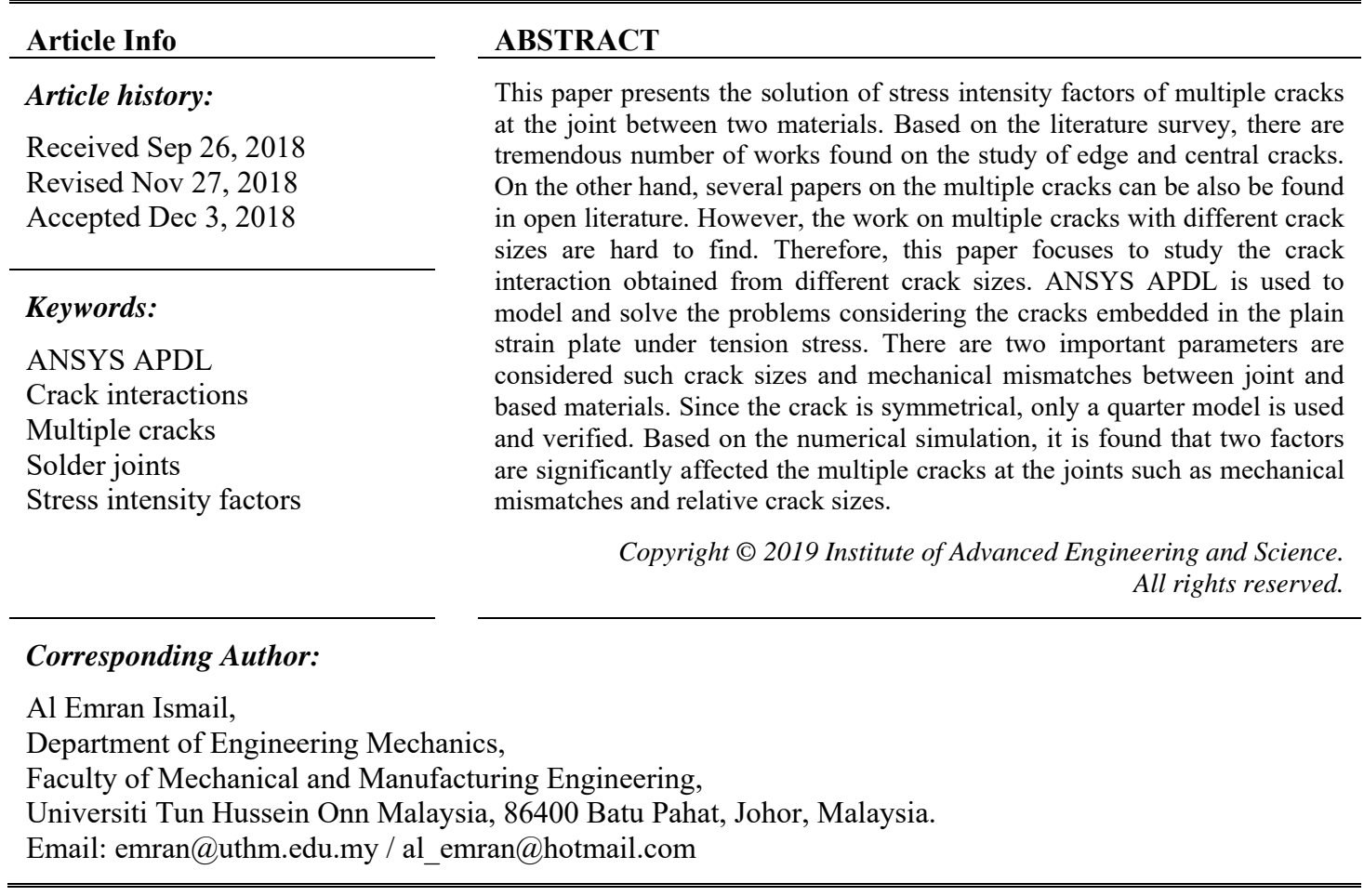

\section{INTRODUCTION}

Most of electronic devices experienced thermo-mechanical fatigue during services. Soldered joints are used to connect different electronic parts and therefore provided the way to transfer electrical currents. Due to the imperfection of joints, cracks may appeared especially at the interface between two materials. In general, the concept of Linear Elastic Fracture Mechanics (LEFM) is used to characterize such cracks in order to determine the reliability of the joints. For example Huang et al. [1] provided a general methodology for calculating mixed mode stress intensity factor of interfacial cracks. In this work, only a single crack is focused considering single-edge crack in plain strain condition. Tsai [2] performed a study on the mode I energy release rate of soldered joints containing a single crack using finite element analysis considering a method of virtual crack closure. It is only considered a single crack between two parts. Another similar work can be found in [3]. Fundamental work on the interfacial cracks between two dissimilar materials are available in [4-7]. Most of these papers discussed on the effect of dissimilar materials on the single crack. It is hard to find the works on the multiple cracks or crack interactions in different material behavior.

Comninou [8] provided an overview work on the interfacial cracks between two different materials considering the LEFM. Atkinsons' first and second models are applied in analyzing the interfacial cracks. In this work, only a single crack is considered. There are several works found in discussing the role of multiple interfacial cracks for an example Monfared et al. [9] studied on the dissimilar materials with multiple cracks. It is positioned exactly between two materials where the crack geometry is identical. 
On the other hand, Bidokhti and Shahani [10] also studied the multiple cracks however the cracks are non-aligned. Meanwhile, Wen et al. [11] also studied the multiple surface cracks under fatigue loading. In this work, cracks are co-planar with both identical and non-identical sizes of three-dimensional models. The results are then compared with ASME, BS7910, API579 and GB/T19624 codes of standard. Then, they suggested a new combination rule and concluded that it always yields a reasonable estimation with necessary conservatism for various initial crack depth, material constant and relative sizes of two cracks. Ismail [12] investigated numerically the multiple crack interaction in bi-materials plate under mode I tension. Two plates of different materials are perfectly bonded assuming that there is no chemical reaction at the interface. Two cracks are positioned at a distance of $b$ for the interfacial boundary. In this work, identical crack length is used to study the crack interactions when different mechanical mismatch is used. The effect of mechanical mismatch can also be found in [13, 14]. Azlan and Ismail [13] studied the inclined crack in bi-material plates and Ismail [14] examined the crack eccentricity at different distance measured from the interfacial line. However, both works focused on the effect of mechanical mismatch on the single crack. Based on the literature found above, it is seemed that the study on the crack interaction when the crack sizes are unidentical are hard to find.

Therefore, this paper numerically presents the role of multiple cracks embedded at the joint. There are two cracks of un-identical crack length and embedded at the joint material. ANSYS finite element program is applied through the use of ANSYS Parametric Design Language (APDL). Two important parameters are used to study the crack interactions such mechanical properties mismatch and crack length. J-integral is used to calculate the crack driving forces and then convert into stress intensity factors. It is selected since the use of singular element around the crack tip is unnecessary.

\section{RESEARCH METHOD}

In this work, three multiple cracks are modelled using ANSYS APDL finite element program as in Figure 1. It is assumed that the model fulfilled a plain strain condition and subjected to axial tension. Since the model is symmetrical, only a quarter model is considered and modelled as in Figure 2 where the vertical left side is assigned as a symmetrical line and on the other hand the bottom line is also assigned as a symmetrical side except the crack faces.

Figure 3 shows the quarter finite element model of multiple crack under tension force. It is meshed using PLANE183 element type assuming to fulfill the plain strain condition. The model is constructed using ANSYS Parametric Design Language (APDL). In this work, J-integral is used as a crack driving force before it is converted into Stress Intensity Factor (SIF) as in (1). Since J-integral is used, it is not required to use singular elements around the crack tip. Figure 4 shows the deformed plate contained multiple cracks under tensile force. In order to study the effect of dissimilar materials, the factor of mechanical mismatch, $e$ is used as in (2). Three values of e are used such as 1, 5 and 10. In this work, the height ratio of joint is kept constant where $h / W=0.02$ and Table 1 summarized the crack parameters used.

$$
K=\sqrt{\frac{J E}{1-v^{2}}}
$$

where, $\mathrm{J}$ is the value of $\mathrm{J}$-integral, $K$ is a stress intensity factor, $E$ is a modulus of elasticity and $v$ is a Poisson's ratio.

$$
e=\frac{E_{1}}{E_{2}}
$$

where, $e$ is a mismatch factor, $E_{1}$ is a modulus of elasticity for plate material and $E_{2}$ is a modulus of elasticity for soldered material. Before any further analysis, it is important to validate the present model with the existing solutions. It is hard to find the multiple cracks in dissimilar or solder joints. Then, it is assumed that the solution obtained from homogenous plate and single crack (Lan et al. [7] and Yan \& Miao [15]) as in Figures 5 and 6. It is observed that for both type of cracks (double edge and central cracks), the present cracks are well agreed with the existing solutions and verified for the further applications.

Stress intensity factors, $K$ obtained from ANSYS finite element program is normalized as follow:

$$
F=\frac{K}{\sigma \sqrt{\pi a}}
$$


where, $F$ is a normalized SIF or geometrical correction factors, $K$ is the SIF, $\sigma$ is the applied stress and a is the crack length. In order to study the interaction among the cracks, an interaction factor, $\gamma$ is then introduced as below:

$$
\gamma=\frac{F_{\text {central crack }}}{F_{\text {edge crack }}}
$$

where $F_{\text {central_crack }}$ and $F_{\text {edge_crack }}$ are the normalized SIFs obtained from central crack (crack length, $a_{1}$ ) and edge crack (crack length, $a_{2}$ ), respectively.

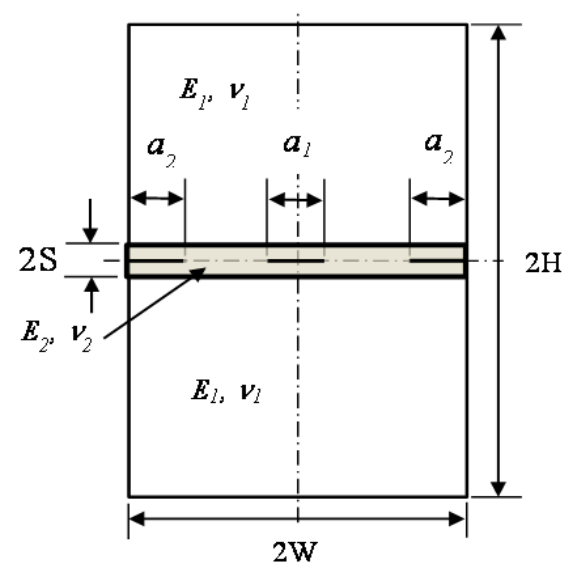

Figure 1. Multiple three crack at the solder joint

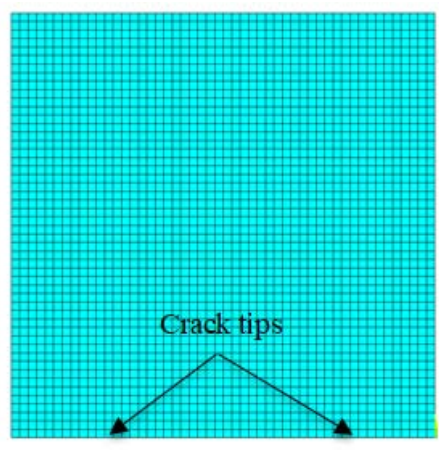

Figure 3. Finite element model of multiple cracks

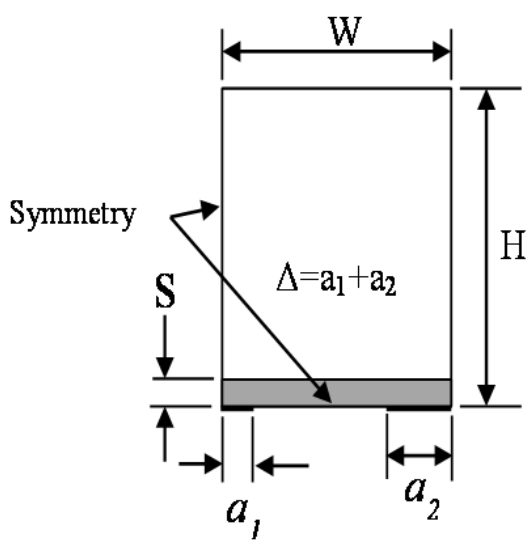

Figure 2. Quarter model of the solder joint with multiple cracks

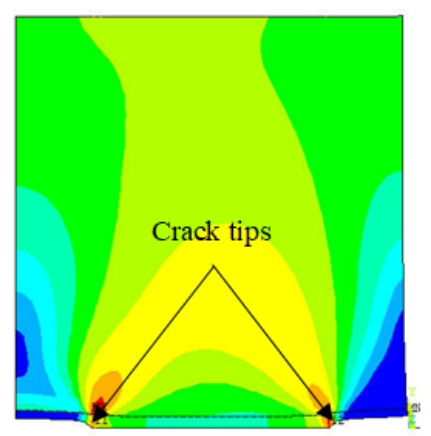

Figure 4. Finite element results of multiple cracks

Table 1. Summary of Crack Parameters

\begin{tabular}{llllll}
\hline$a_{1} / W$ & $a_{2} / W$ & $W$ & $h / W$ & $a_{1}$ & $a_{2}$ \\
\hline 0.1 & 0.1 & 50 & 1 & 5 & 5 \\
0.2 & 0.1 & 50 & 1 & 10 & 5 \\
0.3 & 0.1 & 50 & 1 & 15 & 5 \\
0.4 & 0.1 & 50 & 1 & 20 & 5 \\
0.5 & 0.1 & 50 & 1 & 25 & 5 \\
0.6 & 0.1 & 50 & 1 & 30 & 5 \\
0.7 & 0.1 & 50 & 1 & 35 & 5 \\
0.8 & 0.1 & 50 & 1 & 40 & 5 \\
\hline
\end{tabular}

*Note: The parameter $a_{2} / W$ is also varied starting from 0.1 to 0.8 . 


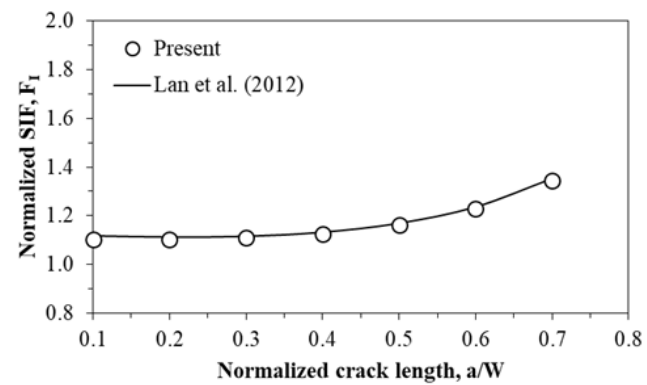

Figure 5. Model validation of double edge crack under tension force

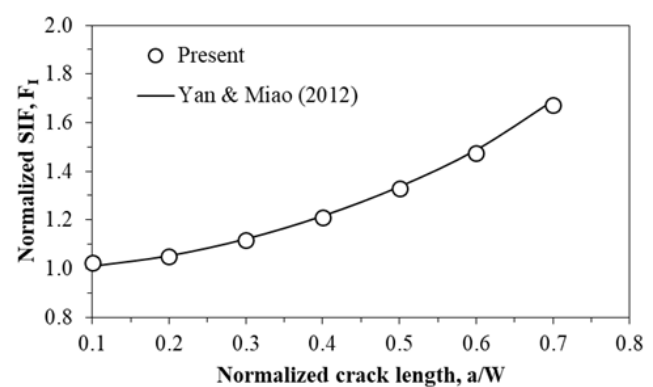

Figure 6. Model validation of central crack under tension force

\section{RESULTS AND ANALYSIS}

This section is divided into two separate sections. The first section deals with the effect of normalized edge crack length, $a_{2} / W$ on the interaction factor, $\gamma$. The second part on the effect of mechanical mismatch, $e$ on the interaction factor, $\gamma$.

\subsection{Effect of Normalized Edge Crack Length, a2/W on the Interaction Factor, $\gamma$.}

Figure 7 shows the roles of normalized central crack length, $a_{1} / W$ on the interaction factor, $\gamma$ when mechanical mismatch is kept as a constant parameter. As shown in (4), the factor of crack interaction is defined as the ratio between SIFs of central cracks over the edge cracks. Higher the interaction factor indicating that the SIFs of central cracks are higher than the SIFs for edge cracks. It is observed that as in Figure 7, interaction factors increased as the function of the length of central cracks. Many research works have reported similar results and can be found in [7-14].

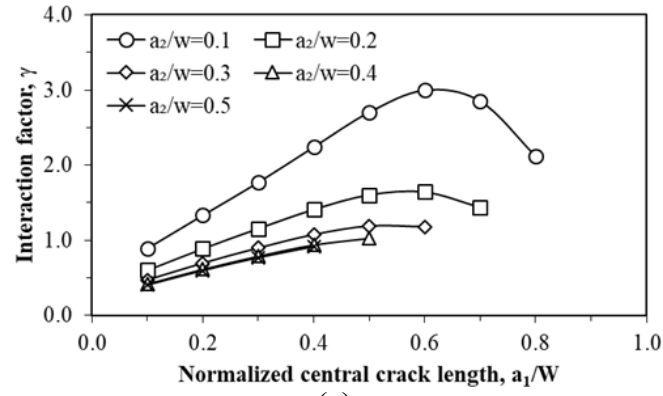

(a)

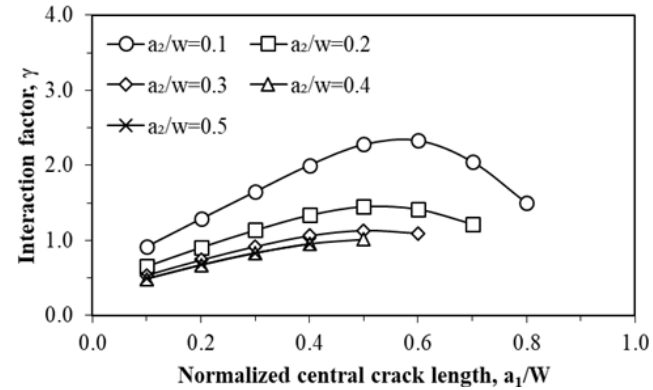

(b)

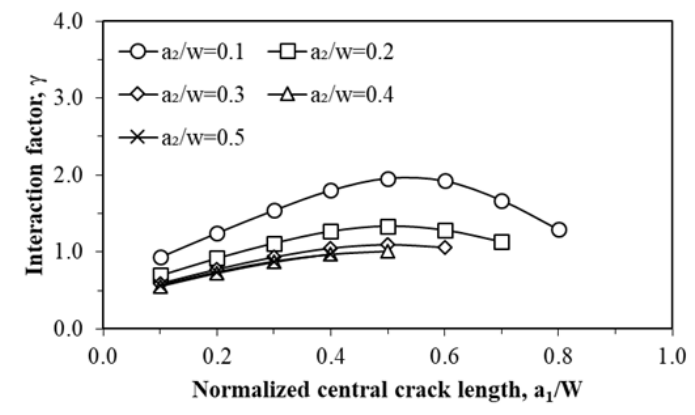

Figure 7. Effect of normalized edge crack length, $a_{1} / W$ on the SIFs when different mechanical mismatches, $e$ are varied, (a) $e=1.0$, (b) $e=5.0$ and (c) $e=10.0$ 
On the other when the normalized edge cracks increased the interaction factors are also decreased. This is due to the fact that for the case of $E_{1}>E_{2}$, the resistance of joint is lower than the upper and bottom plates. This condition created a large joint deformation and therefore producing higher values of SIFs. In comparison these SIFs are higher than the SIFs when $E_{1}<E_{2}$. Figures 7(a)-7(c) reveal the interaction factors for different values of mechanical mismatch, $e=1.0,5.0$ and 10.0, respectively. It is observed that the mechanical mismatch played an important role in determining the interaction factors especially for the case of $a_{2} / W=0.1$ and 0.2 where increasing the mismatch values capable to reduce the interaction factors.

\subsection{Effect of Mechanical Mismatch, $\boldsymbol{e}$ on the Interaction Factor, $\gamma$.}

Figure 8 shows the effect of mechanical mismatches, $e$ on the interaction factor, $\gamma$ when normalized edge cracks, $a_{2} / W$ are varied. In general, when the value of mechanical mismatch increased, there is insignificant effect on the interaction factors especially when higher value of $a_{2} / W$ is used. On the other hand, lower interaction factors can be observed when longer edge cracks are introduced. This is indicated that the interaction factor is significantly related to the relative length between two interacted cracks. Figure 6(a) shows the behavior of interaction factor for the case of $a_{2} / W=0.1$ where both cracks are similar in size. When both cracks are identical, the effect of mechanical mismatch on the crack interaction is obvious where it is decreased when the mismatch factor is decreased.

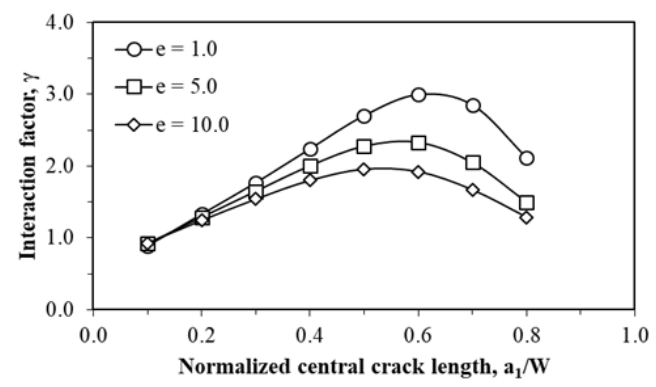

(a)

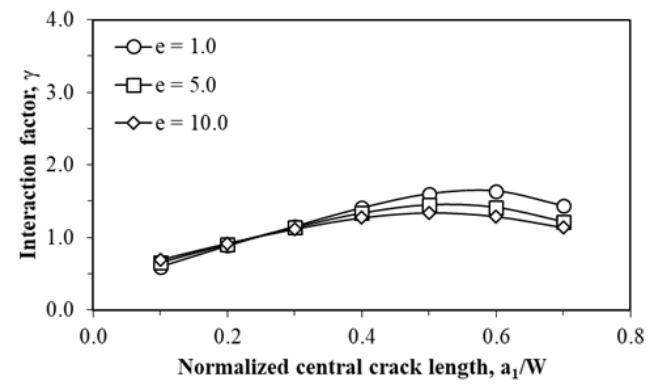

(b)

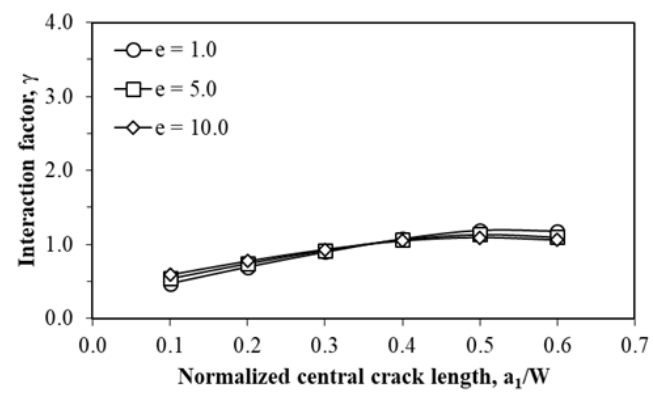

(c)

Figure 8. Effect of mechanical mismatches, $e$ on the interaction factor, $\gamma$ for different normalized edge crack, (a) $a_{2} / W=0.1$, (b) $a_{2} / W=0.2$ and (c) $a_{2} / W=0.3$

\section{CONCLUSION}

Based on the numerical simulations, several main conclusions can be listed as below:

a) It is observed in general that the interaction factor reduced when the mechanical mismatch is increased.

b) It is also observed that the interaction factor converged into a single value when the $a_{2} / W$ is greater than 0.3 .

\section{ACKNOWLEDGEMENTS}

Authors acknowledge Universiti Tun Hussein Onn Malaysia (UTHM) and Kementerian Pengajian Tinggi (KPT) for financially sponsoring this work through the Fundamental Research Grant Scheme (FRGS) 
vot. 1592

\section{REFERENCES}

[1] Z. Huang, P. Kumar, I. Dutta, J.H.L Pang and R. Sidhu, "A general methodology for calculating mixed mode stress intensity factors and fracture toughness of solder joints with interfacial cracks", Engineering Fracture Mechanics, vol. 131, pp. 9-25, 2014.

[2] G.C, Tsai, "Paramteric study of mode I energy release rate of soldered joints", Finite Elements in Analysis and Design, vol. 38, pp. 671-689, 2002.

[3] M.O Alam, H. Lu, C. Bailey and Y.C Chan, "Finite-element simulation of stress intensity factors in solder joint intermetallic compound", IEEE Transaction on Device and Materials Reliability, vol. 9, pp. 40-48, 2009.

[4] D. Sutula, P. Kerfriden, T. van Dam and S.P.A Bordas, "Minimum energy multiple crack propagation. Part 1: Theory and state of the art review", Engineering Fracture Mechanics, vol. 191, pp. 205-224, 2018.

[5] J.R Rice, "Elastic fracture mechanics concepts for interfacial cracks", Journal of Applied Mechanics, vol. 55, pp. 98-103, 1988.

[6] C. Hwu and T.L Kuo, "A unified definition for stress intensity factors of interface corners and cracks", International Journal of Solids and Structures, vol. 44, pp. 6340-6359, 2007.

[7] X. Lan, N.A Noda, K. Mithinaka, Y. Zhang, "The effect of material combinations and relative crack size to the stress intensity factors at the crack of a bi-material bonded strip", Engineering Fracture Mechanics, vol. 78, pp. 2572-2584, 2011.

[8] M. Comninou, “An overview of interface cracks", Engineering Fracture Mechanics, vol. 37, pp. 197-208, 1990.

[9] M.M. Monfared, M. Ayatollahi, R. Bagheri, "In-plane stress analysis of dissimilar materials with multiple interface cracks", Applied Mathematical Modelling, vol. 40, pp. 8464-8474, 2016.

[10] A.A. Bidokhti, A.R. Shahani, "Interaction analysis of non-aligned cracks using extended finite element method", Latin American Journal of Solids and Structures, vol. 12, pp. 2439-2459, 2015.

[11] J-F. Wen, Y. Zhan, S-T. Tu, F-Z. Xuan, "A combination rule for multiple surface cracks based on fatigue crack growth life", AIMS Materials Sciences, vol. 3, pp. 1649-1664, 2016.

[12] A.E. Ismail, "Multiple crack interaction in bi-material plates under mode I tension loading", Applied Mechanics and Materials, vol. 629, pp. 57-61, 2014.

[13] M.A. Azlan, A.E. Ismail, "Effect of mechanical mismatch on the stress intensity factors of inclined cracks under mode I tension loading", Applied Mechanics and Materials, vol. 773-774, pp. 129-133, 2015.

[14] A.E. Ismail, "Stress intensity factors of eccentric cracks in bi-materials plate under mode I loading", AIP Conference Proceedings, vol. 1660, 070029, 2015.

[15] X. Yan, C. Miao, "Interaction of multiple cracks in a rectangular plate", Applied Mathematics Modelling, vol. 36, pp. 5727-5740.

\section{BIOGRAPHY OF AUTHOR}

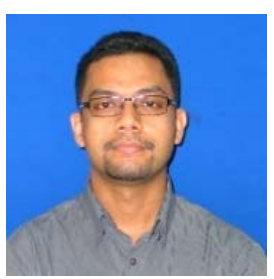

Dr. Al Emran Ismail is an associate professor in the faculty of mechanical and manufacturing engineering, Universiti Tun Hussein Onn Malaysia (UTHM). His focus areas are fracture mechanics, finite element analysis and crashworthiness. For more detail, please visit: https://community.uthm.edu.my/emran 